\title{
AVALIAR PROJETO METODOLÓGICO: ISTO É POSSÍVEL?
}

\author{
Marisa Aparecida Pereira Santos* \\ Carolina Nunes Pegoraro ** \\ ILDA BASSO $* * *$ \\ Maria Auxiliadora de Castilho**** \\ Thiago Macedo SiLVeStRE*****
}

Recebido: jun. $2010 \quad$ Aprovado: fev. 2011

\begin{abstract}
*Doutora em Educação pela USP, campus São Paulo. Professora titular da Universidade Sagrado Coração (USC), Bauru, SP, Brasil. Presidente da Comissão Própria de Avaliação e coordenadora de projetos didáticos pedagógicos na USC.É avaliadora institucional do MEC. E-mail: marisa.santos@usc.br

**Doutora em Odontologia, área de Dentística, pela Universidade de São Paulo. Professora assistente I da Universidade Sagrado Coração, Bauru, SP, Brasil. Atua na Coordenadoria Didática da USC. E-mail: carolnpeg@gmail.com

***Doutora em Educação pela Universidade Estadual de Campinas. Docente do Centro de Ciências Humanas da Universidade do Sagrado Coração, Bauru, SP, Brasil. E-mail: irilda@usc.br

****Mestranda em Administração de Empresas pela Escola de Administração de Empresas de São Paulo FGV. Coordenadora Financeira da USC, Bauru, SP, Brasil. E-mail: irdorinha@usc.br

*****Aluno do curso de Ciência da Computação na Universidade Sagrado Coração Bauru, SP, Brasil. Responsável pelo suporte técnico da Plataforma Syllabus. E-mail: thiago.silvestre@usc.br
\end{abstract}

Resumo: O objetivo deste trabalho é relatar os resultados da avaliação somativa do Projeto Pedagógico Syllabus, implantado no início de 2008, nos cursos de graduação oferecidos pela Universidade Sagrado Coração (USC), localizada na cidade de Bauru, no interior do Estado de São Paulo. Para isso, avaliou-se o desempenho de uma amostragem de estudantes da USC, ingressantes dos cursos de Pedagogia, História, Arquitetura e Urbanismo e Ciência da Computação, que durante um ano utilizaram a metodologia Syllabus, nas questões de formação geral do ENADE/2008. Os dados analisados são relativos à comparação do desempenho dos estudantes da USC com estudantes dos mesmos cursos em outras instituições de Ensino Superior, localizadas na região de Bauru, e também com a média geral dos estudantes destes cursos no Brasil. Foram ainda analisados os resultados de uma avaliação interna feita pela Universidade em 2009, sobre a aplicação desta nova metodologia de ensino-aprendizagem. Com relação ao desempenho nas questões do ENADE/2008, observou-se que os melhores resultados foram obtidos pelos estudantes da USC. Além disso, verificou-se que os estudantes de Pedagogia e História, que obtiveram, dentre os cursos avaliados, o melhor desempenho nas questões de formação geral do ENADE/2008, foram os que apontaram na avaliação da metodologia, o maior índice de participação nas Leituras e Atividades Prévias recomendadas pelos docentes. As evidências encontradas sugerem que a metodologia Syllabus tem apresentado um impacto positivo na aprendizagem dos universitários.

Palavras-chave: Metodologia de ensino-aprendizagem; Avaliação.;Avaliação institucional; Syllabus.

\section{TO EVALUATE THE METHODOLOGICAL PROJECT: IS IT POSSIBLE?}

Abstract: The aim of this study is to report the results of evaluation of the Syllabus Pedagogical Project, implemented in the beginning of 2008, in undergraduate programs at Universidade Sagrado Coração (USC), located in Bauru, State of São Paulo. With this intent, a sample of the performance of first year USC Pedagogy, History, Architecture and Urban Design and Computer Science students, who 
used the Syllabus methodology for one year, was analyzed. The analysis referred to questions of general training of ENADE/2008. The analyzed data apply to the comparison of USC students performance with that of students of the same programs at other institutions, like Colleges or Universities, located in Bauru or around it, and also with the average of students of these programs in Brazil. It also analyzed the results of an internal assessment done by the University in 2009 about the implementation of this new methodology of teaching and learning. With respect to performance issues of ENADE/2008, it has been observed that the best results were obtained by students of USC. Moreover, the students of Pedagogy and History, who performed best in ENADE/2008, among the programs evaluated, were those who indicated in the evaluation of the methodology, the highest level of participation in reading and Prior Activities recommended by teachers. The results suggest that the Syllabus methodology has made a positive impact on students' learning.

Key words: Methodology of teaching and learning; Evaluation; Institutional evaluation; Syllabus.

\section{INTRODUÇÃO}

Para atender a demanda social e acompanhar a evolução da educação, as políticas educacionais brasileiras adotaram nos últimos anos, como diretrizes didáticas e pedagógicas, a avaliação como ponto de destaque no processo de aprendizagem e construção do conhecimento.

A avaliação assumiu grande importância nas políticas dos governos, devido ao crescimento das avaliações externas, como forma de medir a evolução educacional de um país, e, consequentemente, as escolas também passaram a trabalhar com um olhar voltado para essas avaliações externas (RODRIGUES, 2008, p. 1).

O sentido de avaliar, relacionando resultados e aspectos determinantes define dois tipos de avaliação diagnóstica, a formativa, no ato de deduzir a probabilidade de um programa atingir objetivos, e a somativa, que verifica se o programa atingiu ou vem atingindo os objetivos. O processo avaliativo:

precisa estar voltado para melhoria da aprendizagem e ajuste de processos metodológicos, para que assim viabilize uma avaliação formativa, a qual se fundamenta nos princípios do cognitivismo, nas teorias socioculturais e nas sociocognitivas (TEIXEIRA, 2009, p. 31).

$\mathrm{Na}$ avaliação formativa, o diagnóstico corresponde ao julgamento de aspectos e experiências mediante a comparação entre os resultados dos levantamentos feitos. Já a avaliação somativa pode ser feita por meio da mensuração de impacto, ou seja, pesquisando as condições de empregabilidade ou possibilidade de análise de satisfação, considerando como hipótese que a avaliação "não está ao final do processo e sim no significado de perseguir as etapas percorridas com efetivo acompanhamento de todas possibilidades de procedimentos." (HOFMANN, 1993, p. 150). 
Estudiosos e teóricos da educação buscam dar resposta a esta complexa atividade de avaliar. Desse modo, novas adjetivações foram surgindo tais como emancipatória, diagnóstica, qualitativa e processual, entre outras. Entretanto, nada disso muda sua razão maior de ser, que é a de cuidar do aprendizado do aluno. Isto porque não se deve avaliar para emitir uma nota e sim para promover o aprendizado. Segundo Sordi (2008), a avaliação deve colocar-se a serviço da aprendizagem, assistindo ao professor e aos estudantes, orientando-os formativamente a reverem seus avanços e fragilidades além de construírem possibilidades de superação, rumo ao alcance das competências pactuadas no seu fazer pedagógico. Sem a avaliação "fica-se desprovido de evidências que permitam monitorar e interferir precocemente nas condições que prejudicam ou potencializam a obtenção dos objetivos educacionais pretendidos" (SORDI, 2009, p. 314). De acordo com Assman e Mo Sung (2000), a avaliação pode tornar-se algo muito agradável se for cercada de cuidado, no pleno sentido do termo, incluindo envolvimento e encanto.

Para alcançar esse objetivo, a avaliação não deve ser um ato mecânico, no qual o professor aplica provas e atividades, o estudante as realiza, sendo lhe dado um conceito para transmitir a medição do conhecimento. A avaliação tem que ser um ato, no qual a reflexão seja inerente, contribuindo para a construção de competências técnicas e sócio-político-culturais (RODRIGUES, 2008, p. 1).

Este artigo relata a análise dos resultados da avaliação somativa do Projeto Pedagógico Syllabus, implantado em 2008, nos cursos de graduação oferecidos pela Universidade Sagrado Coração (USC), localizada na cidade de Bauru, no interior do Estado de São Paulo. O projeto visa inovar as estratégias metodológicas no Ensino Superior a fim de que o aluno venha preparado para o encontro pedagógico que ocorre em sala de aula, e participe ativamente da construção de seu conhecimento. Esta metodologia é embasada na premissa de que para o estudante aprenda a ser crítico, há necessidade de investimentos na relação ensino-aprendizagem, focando o ambiente da sala de aula como gerador da sinergia que move a aprendizagem e a construção do conhecimento.

As diretrizes fundamentais do Projeto Syllabus provêm do modelo pedagógico aplicado na Universidade Santo Tomás (UST) do Chile, introduzido pelos educadores Ernesto Schiefelbein, Doutor em Educação pela Universidade de Harvard e Reitor da Universidade Santo Tomás de 1996 a 2001, e Ricardo Zúñiga, Decano do Centro de Ciências Sociais e Humanas da mesma Universidade no período de 1997 a 2007 (SANTOS; NASKASHIMA; PEGORARO; 
ZUCCARI, 2009, p. 23). A palavra Syllabus é de origem grega e além de plano de atividades e programa de estudos a ser desenvolvido, tem sentido de detalhar, enumerar e especificar os componentes de um conjunto (HEVIA; ZÚÑIGA; SCHIEFELBEIN 2002, p. 86).

A perspectiva do êxito desta metodologia de ensino-aprendizagem compromete o planejamento e a avaliação das disciplinas e seus respectivos programas de ensino nos cursos. Sendo assim, estabelece a avaliação processual e somativa das etapas de desenvolvimento como fator de relevância. O processo avaliativo do projeto é orientado pela Coordenadoria Didática e Pedagógica da Universidade, responsável pela formação continuada dos professores e coordenação do Projeto Pedagógico adotado. O seu papel é exercer uma gestão educativa, procurando desvendar as dificuldades dos professores e orientá-los de forma que se efetive o apoio didático-pedagógico da prática docente no decorrer do projeto.

\section{O PROJETO PEDAGÓGICO SYLLABUS}

Segundo, Gillen (2000, p. 21) "não é possível avaliar o desempenho de alguém sem antes ter uma boa compreensão de seus trabalhos, [...] e uma forma eficaz de fazer isso é considerar o propósito do trabalho e as áreas de resultados-chaves". Assim, discorrer a respeito do impacto do Projeto Syllabus nos cursos de graduação, a serviço da qualidade educacional, pressupõe considerar a relevância dos seus objetivos e sua relação com a avaliação, de forma a considerar, como afirma Teixeira (2009, p. 31), que "a avaliação, para estar a serviço da qualidade educacional, deve, entre outros objetivos, cumprir o seu papel de promoção do ensino, o qual guiará os passos do educador e do aluno".

Desta forma, o trabalho avaliativo visando compreender o impacto desta metodologia no ambiente da sala de aula a ponto de apontar se ele já está sendo ou não responsável pela sinergia que mobiliza a aprendizagem e construção do conhecimento do estudante, implica vários fatores, dentre eles, a relação teoria e prática sobre concepções conceituais e habilidades metodológicas do docente.

Esta relação nos resultados para a avaliação processual e somativa aponta indicadores significativos, conforme mencionou o professor Requena (2010) que atua na disciplina de Comunicação e Expressão, disciplina de formação básica dos cursos de graduação da Instituição, ao participar do Fórum promovido durante a Semana de Estudos e Planejamento Docente (SECOD), no inicio de 2010, na Plataforma Syllabus. Quando questionado se no plano da aula o professor deve destacar quais são os objetivos específicos, ou seja, aquilo que o estudante deverá ser capaz de atingir ao final da aula, relatou que 
é necessário ter em mente, de modo muito claro, qual o objetivo da matéria da aula, por meio do que foi construído e respondido pelos alunos ao final da mesma. Assim, o professor terá os elementos necessários para prosseguir ou retomar o assunto tratado. Não devemos nos esquecer de que as avaliações para se saber se os objetivos específicos da aula foram ou não atingidos, devem ser um diagnóstico para prosseguimento ou retomada do assunto. (REQUENA, 2010)

Segundo Machado (2002, p. 274), a especificação dos objetivos a serem alcançados configura-se uma tarefa possível e necessária, de natureza metodológica em sentido amplo, diretamente associada ao próprio significado etimológico da palavra método, ou seja um caminho para uma meta, um objetivo.

Porém, os elementos necessários mencionados pelo professor consolidam sua viabilidade, já no momento do planejamento da aula, quando ocorre a preparação do professor e do estudante para o encontro pedagógico traduzido como aula. Para Zabala (1998, p. 18), a aula "constitui um conjunto de atividades ordenadas, estruturadas e articuladas para a realização de certos objetivos educacionais que tem um princípio e um fim conhecidos tanto pelos professores como pelos alunos".

Libaneo (1992) afirma que "as aulas podem ser previstas em correspondência com as etapas ou passos do processo de ensino". Neste sentido, o Projeto Pedagógico Syllabus, ao estimular o acesso do aluno, via plataforma, às orientações e indicações de leituras, a resolução de exercícios, a anotações de observações, comparações, resumos dos conhecimentos e eventuais questionamentos como recursos prévios para facilitar o diálogo pedagógico, tem como propósito oferecer meios para ampliar a correspondência com as etapas ou passos do processo de ensino-aprendizagem, estabelecidos no programa da disciplina.

Esses recursos prévios, no Modelo Pedagógico Syllabus, são disponibilizados na plataforma tecnológica Moodle ${ }^{l}$, ambiente aberto que pode ser acessado pelo aluno e professor, de qualquer computador conectado à internet e que ficou caracterizada no ambiente acadêmico da USC como Plataforma Syllabus (http:// syllabus.usc.br). Essa ferramenta se constitui no apoio institucional oferecido como dispositivo didático ao professor para viabilizar e facilitar o hábito da leitura prévia. Entretanto, a política institucional adotada, reforça o conceito de que o espaço educacional virtual não suprime o espaço presencial, e sim amplia o processo de ensino e aprendizagem para o paradigma da tecnologia da informação, não evoluindo para seu fechamento como um sistema (SANTOS; NASKASHIMA; PEGORARO; ZUCCARI, 2009, p. 24).

1 O Moodle é um ambiente de aprendizagem desenvolvido pelo australiano Martin Dougiamas em 1999, utilizado em aproximadamente 120 países. 
A dinâmica do planejamento para o encontro pedagógico entre professor e aluno na metodologia Syllabus, concentra-se no que é essencial para aula atender aos objetivos específicos definidos pelo professor. Ele abrange indicações de leituras complementares ao assunto tratado a fim de viabilizar qualidade para a formação ou modificação da conduta dos alunos. A leitura prévia é "uma estratégia de planejamento [...] que consiste no estabelecimento da interação dos estudantes com a unidade de ensino para facilitar o diálogo com o professor e encorajá-los para indagação sobre os obstáculos que dificultam a compreensão do conteúdo" (SANTOS; NASKASHIMA; PEGORARO; ZUCCARI, 2009, p. 23). Trata-se de "buscar atividades pedagógicas que sejam mais eficientes e mais eficazes para colaborar com a aprendizagem dos alunos e melhorar a qualidade dos cursos de graduação" (MASETTO, 2001, p. 84).

O plano de aula, inserido semanalmente na plataforma, tem o propósito de direcionar as atividades para o domínio cognitivo e das capacidades que se pretende que os alunos desenvolvam nas disciplinas. Nele são inseridos para consulta prévia do estudante, os objetivos específicos que se pretende atingir com a aula; os conteúdos abordados, que devem estar de acordo com os propostos no Plano de Ensino da disciplina; a metodologia que será utilizada na aula; as orientações para o desenvolvimento de uma atividade ou leitura prévia; orientações sobre a realização do Quiz e sugestões para leitura pós-aula.

$\mathrm{O}$ ambiente de aprendizagem desenvolvido com clima participativo e integrado, no Projeto Syllabus, tem como proposta de apoio à atividade prévia e avaliação periódica em sala de aula, denominada como Quiz .

Essa estratégia de apoio, utilizando a aplicação do Quiz como avaliação rápida e processual por meio de um breve questionamento a respeito da atividade prévia disponibilizada para o aluno na plataforma, envolve segundo uma professora inserida no projeto, "aspectos quantitativos e qualitativos. Quantitativo quando considerado o número de participações válidas para determinar o valor agregado à nota do aluno e qualitativos quando estabelecidos os critérios para aceitação ou não do Quiz, para ser considerado válido para a avaliação." (FOLKIS, 2010).

A relação do diagnóstico obtido através do Quiz, como afirmou Requena (2010) no Fórum, permite perceber que determinadas competências são prérequisitos para o domínio de outras e que, portanto, é fundamental que se ajustem as atividades ao nível e às possibilidades dos estudantes, tendo em mente uma visão longitudinal dos objetivos de ensino.

A premissa da metodologia Syllabus é o conhecimento não ser compreendido somente na ação de simplesmente aceitar as informações da maneira como 
elas acontecem muitas vezes no ensino tradicional, mas sim, proporcionar ao estudante, antes de tudo, oferta do aprendizado para refletir e questionar situações. Dessa forma, estimula práticas pedagógicas interdisciplinares, que segundo Noronha $(2009$, p. 22$)$ requerem trabalho conjugado e cooperativo dos professores no planejamento e na execução dos planos de ensino. Enfim, a Metodologia Syllabus opera na dinâmica de ação junto à concepção de ensino e aprendizagem e visa revitalizar os procedimentos didáticos e pedagógicos dos professores, estimulando a participação do estudante no processo de aprendizado para atender os objetivos das disciplinas que compõem os currículos dos cursos.

\section{PRÁTICA DE AVALIAÇÃO DO PROJETO PEDAGÓGICO SYLLABUS}

Os critérios de avaliação dependem da concepção de mundo que orientam o trabalho das instituições de educação as quais se aplicam (WACHOWICZ, 2000, p. 99). De acordo com Luckesi (2002), o processo avaliativo está relacionado ao contexto educacional da época e "[...] não se dá nem se dará num vazio conceitual, mas sim dimensionada por um modelo teórico de mundo e, conseqüentemente de educação, que possa ser traduzido em prática pedagógica". A prática da avaliação, segundo os conceitos de Figari (1996), traz noção de estrutura, macroestruturas (sistemas educativos), mesoestruturas (estabelecimentos de ensino) e microestruturas (turmas de alunos).

Em relação à avaliação do Projeto Pedagógico Syllabus em termos de macroestrutura, evidencia-se insipiência de resultados a respeito do processo de avaliação externa no que tange ao Exame Nacional de Avaliação e Desempenho do Estudante (ENADE). Segundo a Lei ${ }^{\circ}$ 10.861/04 que instituiu o Sistema Nacional de Avaliação da Educação Superior - SINAES, no seu art. $5^{\circ}$, designa o ENADE para aferir

o desempenho dos estudantes em relação aos conteúdos programáticos previstos nas diretrizes curriculares do respectivo curso de graduação, para ajustamento às exigências decorrentes da evolução do conhecimento e suas competências para compreender temas exteriores ao âmbito específico de sua profissão, ligados à realidade brasileira e mundial e outras áreas do conhecimento (p. 4)

A metodologia Syllabus, adotada pela Universidade Sagrado Coração, ainda não apresenta concluintes de cursos. Dessa forma, entre os estudantes que participam do projeto, apenas os ingressantes em 2008 participaram da prova 
do ENADE. Por isso, neste estudo, para embasar a discussão sobre o primeiro impacto da metodologia Syllabus, foram considerados os dados de desempenho na prova de formação geral do ENADE/2008 de uma amostragem de estudantes que durante um ano utilizaram a metodologia. A amostragem corresponde a alunos ingressantes dos cursos de Pedagogia e História (Centro de Ciências Humanas), Arquitetura e Urbanismo e Ciências da Computação (Centro de Ciências Exatas e Sociais Aplicadas). Os dados são relativos à comparação com outros estudantes dos mesmos cursos em outras instituições de Ensino Superior localizadas na região de Bauru, como também a média dos estudantes obtida no Brasil.

As figuras 1,2, 3 e 4 demonstram a média de desempenho dos ingressantes dos cursos avaliados, nas questões de formação geral, comparando os resultados da USC com outras instituições de Bauru e região, aqui especificadas como A, $\mathrm{B}, \mathrm{C}$ e $\mathrm{D}$ e com a média nacional.

Figura 1 - Comparação entre a média obtida pelos estudantes ingressantes do curso de Pedagogia na Universidade Sagrado Coração (USC), estudantes de Instituições de Ensino Superior localizadas em Bauru (SP) e região - Instituição A, Instituição B, Instituição C - e média dos estudantes ingressantes brasileiros neste curso. Formação geral -ENADE/ 2008.

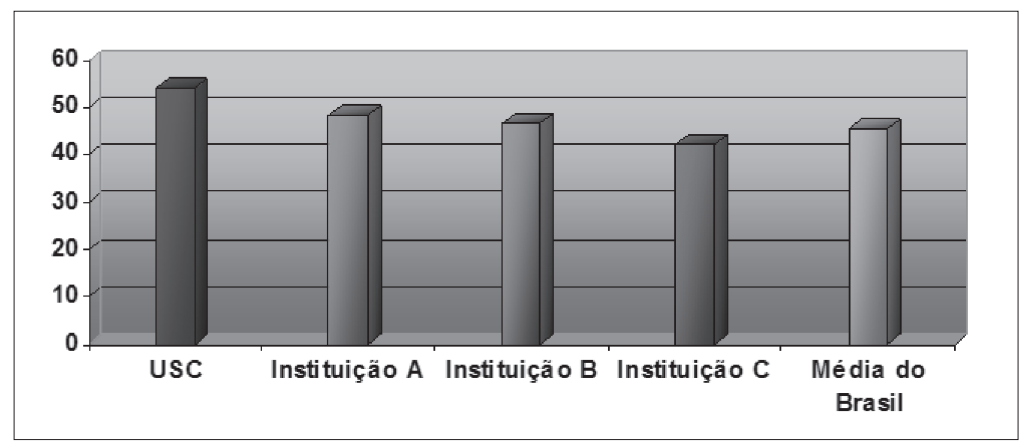

O curso de Pedagogia da USC, reconhecido pelo MEC pela primeira vez em 1956, é integrado administrativamente ao Centro de Ciências Humanas em consonância com o Plano de Desenvolvimento Institucional e assume, com base no compromisso e engajamento do corpo docente, discente e técnicoadministrativo, a tarefa de transformar o ensino, pesquisa e extensão no processo de formação do estudante para o mercado de trabalho, garantindo ações 
educativas, flexíveis e condizentes com a filosofia e Missão Institucional (USC, 2008, p. 13). Com relação ao desempenho no ENADE, na prova de formação geral, é possível verificar que o curso se destaca com resultado satisfatório quando comparado ao desempenho de ingressantes das demais instituições especificadas no gráfico. Verifica-se na Figura 1 que os ingressantes da USC, cuja média foi 54,1, obtiveram rendimento melhor que a Instituição A (média 48,2), Instituição B (média 46,67) e Instituição C (média 42,1) e melhor também que a média brasileira que foi igual a 45,5 . Esta diferença entre as médias foi respectivamente de $5,9,7,4,11,9$ e 8,6 .

Figura 2 - Comparação entre a média obtida pelos estudantes ingressantes do curso de História na Universidade Sagrado Coração (USC) e média dos estudantes ingressantes brasileiros neste curso. Formação geral - ENADE/ 2008.

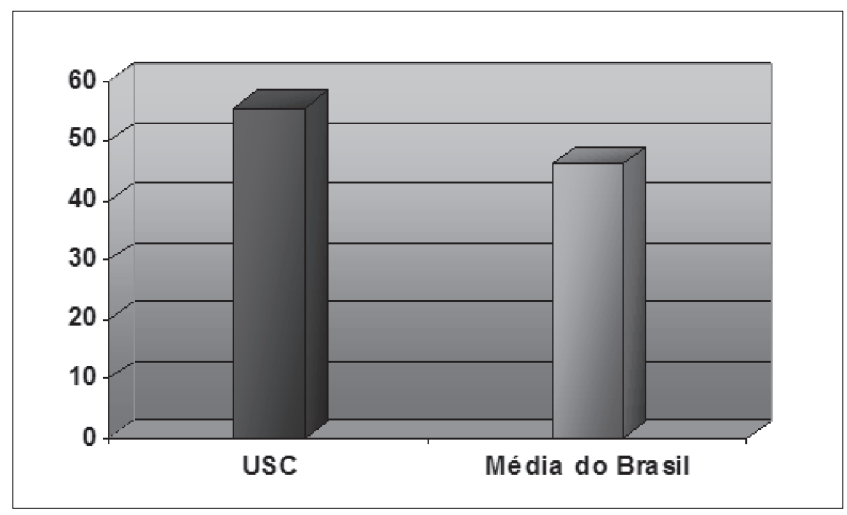

O curso de História da Instituição, o único de Bauru e região, também reconhecido pelo MEC em 1956, tem como objetivo, segundo o seu Projeto Pedagógico (2008, p. 32), formar profissionais conscientes e comprometidos com o ensino, inseridos na realidade nacional, capazes de responder às demandas sociais relativas ao seu campo de conhecimento, promovendo as transformações sociais possíveis e necessárias, para as quais o universo histórico é imprescindível. Conforme se verifica na figura 2, os ingressantes do curso apresentaram no ENADE um resultado plenamente satisfatório (média 55,3) quando comparado com a média de desempenho dos ingressantes brasileiros $(46,1)$. A diferença entre as médias foi de 9,2. 
Figura 3 - Comparação entre a média obtida pelos estudantes ingressantes do curso de Arquitetura e Urbanismo na Universidade Sagrado Coração (USC), estudantes de uma Instituição de Ensino Superior localizada em Bauru- Instituição D - e média dos estudantes brasileiros neste curso. Formação geral - ENADE/ 2008.

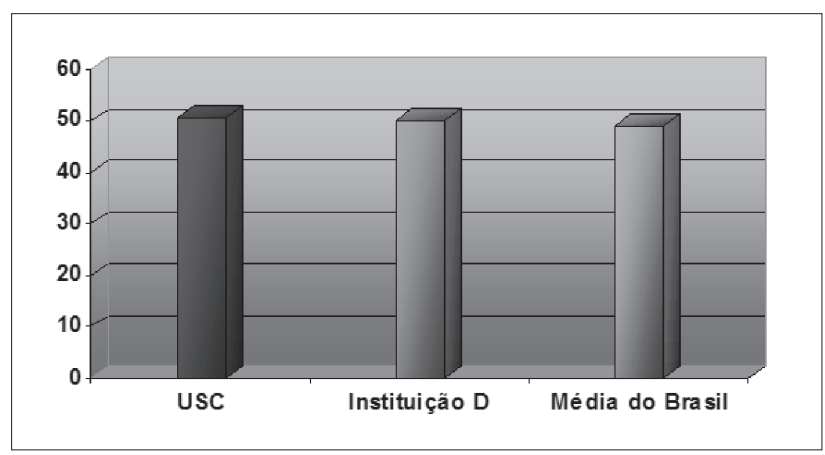

O curso de Arquitetura e Urbanismo é novo na USC. Autorizado pelo Conselho Universitário, no Parecer/USC 2/2008, apresenta como proposta um Projeto Pedagógico baseado nas diretrizes gerais do Ministério da Educação, nos Conselhos Federais e Estaduais de Arquitetura (CONFEA e CREA) e na filosofia humanista cristã que norteia todos os cursos da Instituição. Como retrata a figura 3, os ingressantes do curso na Instituição apresentaram um desempenho (média 50,6) acima da média da Instituição D $(50,2)$, com a qual foi comparada e também acima da média geral dos ingressantes brasileiros $(49,2)$. A diferença entre as médias foi pequena, mas suficiente para evidenciar o potencial dos estudantes na prova de formação geral.

O curso de Ciência da Computação tem definido no seu Projeto Pedagógico (2008) uma linha metodológica que propõe a relação ensino e aprendizagem, tendo como sujeito o ser humano em todas as suas dimensões, com conteúdos específicos da computação e a utilização de técnicas baseadas no domínio dos conhecimentos, habilidades e aptidões indispensáveis à atuação deste profissional na sociedade. Com relação ao desempenho no ENADE, é possível verificar que o curso se destacou, com resultado satisfatório (média 48,3) quando comparado ao desempenho das Instituições A (média 45,4) e Instituição D (média $41,8)$ e também com relação à média brasileira (média 47). Esta diferença entre as médias foi respectivamente de 2,9, 6,5 e 1,3.

Embora os resultados dos estudantes ingressantes dos cursos da área de Ciências Exatas e Sociais Aplicadas sejam satisfatórios quando comparados 
Figura 4- Comparação entre a média obtida pelos estudantes ingressantes do curso de Ciências da Computação na Universidade Sagrado Coração (USC), estudantes de duas Instituições de Ensino Superior localizadas em Bauru e região - Instituição A e Instituição D - e média dos estudantes brasileiros neste curso.Formação geral -ENADE/ 2008.

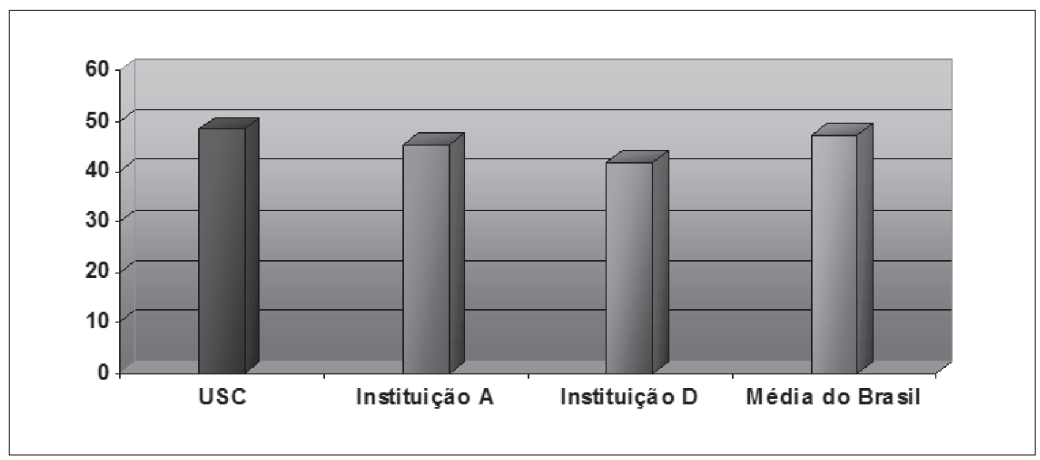

com a média dos estudantes brasileiros nestes cursos, conforme demonstram as figuras 3 e 4, fica evidente que a atividade prévia pode desencadear o desenvolvimento das competências estabelecidas pelas disciplinas básicas, porém, não na mesma dimensão demonstrada pelos cursos da área de Ciências Humanas (Figuras 1 e 2).

Ao visualizar as Figuras 1 e 2 e compará-las com as Figuras 3 e 4, verifica-se que existe evidência de que na formação dos estudantes ingressantes em cursos da área de Ciências Humanas, a leitura atua de forma mais efetiva em relação aos ingressantes das Ciências de Exatas e Sociais Aplicadas. Esta análise reforça a necessidade de estimular a criatividade, tanto do professor como do aluno dos cursos das áreas de Ciências de Exatas e Sociais Aplicadas, no sentido de criar e buscar estratégias metodológicas voltadas para o estímulo da aplicação e acompanhamento da atividade prévia, numa abordagem que contribua para ampliar a sua visão de mundo, através da leitura do contexto.

A prática da avaliação institucional implantada nacionalmente traz nos dias de hoje para os estabelecimentos de ensino, fortalecendo a concepção de mesoestruturas definida por Figari (1996), critérios definidos pelo Instituto Nacional de Estudo e Pesquisa (INEP) no sentido de definir valores que expressam o grau de qualidade dos cursos, criando um novo indicador, o Conceito Preliminar de Curso (CPC), que vai de 1 a 5. Este conceito é obtido através da combinação dos resultados do ENADE com fatores que consideram a titulação dos professores, o percentual de docentes que cumprem regime de 
trabalho parcial ou integral, recursos didático-pedagógicos e infra-estrutura da Instituição. Para citar como exemplo, nas últimas avaliações realizadas, o curso de Pedagogia da Instituição obteve nota 4 no ENADE e conceito CPC igual a 3, o curso de História teve nota 4 no ENADE e CPC também 4 e o curso de Ciência da Computação teve nota ENADE 2 e CPC igual a 3.

Figura 5 - Percentual de estudantes matriculados nos cursos de Pedagogia, História, Arquitetura e Urbanismo e Ciência da Computação na Universidade Sagrado Coração que afirmaram que o professor faz na sala de aula perguntas sobre a Atividade Prévia orientada no Plano de aula.

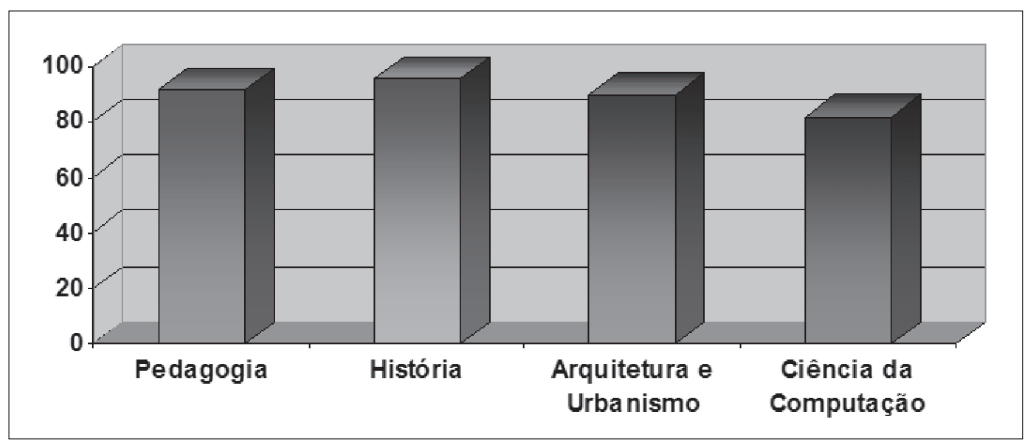

Figura 6 - Percentual de estudantes matriculados nos cursos de Pedagogia, História, Arquitetura e Urbanismo e Ciência da Computação na Universidade Sagrado Coração que afirmaram realizar semanalmente a leitura recomendada pelo Professor na Atividade Prévia do Plano de aula.

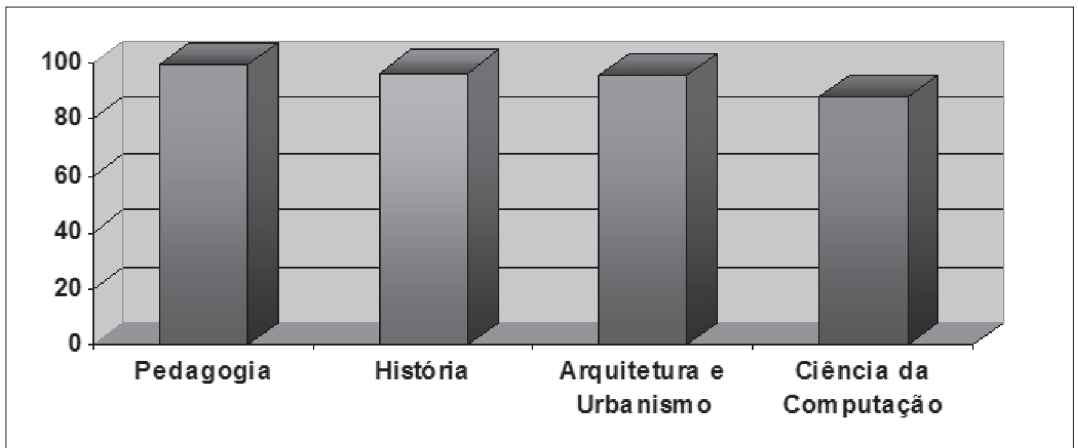


O CPC pode representar para os estabelecimentos de ensino a condenação dos cursos, no mercado de oferta do Ensino Superior, quando os mesmos não corresponderem a uma avaliação considerada referência mínima de qualidade. Dessa forma, a comparação de qualidade entre os estabelecimentos de ensino e o certificado de credibilidade dos cursos, faz do Projeto Syllabus uma alternativa para melhoria da qualidade de ensino e aprendizagem. Por outro lado, evidencia a importância da metodologia ser avaliada na dimensão formativa e autêntica para contribuir com um projeto em processo de implantação. "A avaliação autêntica tem como finalidade melhorar o processo de ensino e aprendizagem, informando e orientando os alunos e responsáveis sobre progressos e dificuldades." (DEPRESBITERIS; TAVARES, 2009, p. 52).

A política institucional de ensino na USC tem como objetivo oferecer formação integral e qualificação profissional ao estudante e está pautada na prática interdisciplinar do ensino, por meio de um currículo que contempla a existência de disciplinas Básicas, disciplinas Comuns de Centro e disciplinas Específicas de curso.

A avaliação de conhecimentos relativos à formação geral a que os estudantes ingressantes nos cursos de graduação em 2008 foram submetidos na prova do ENADE, abordou conteúdos desenvolvidos em disciplinas que formam o bloco básico da formação dos alunos para todos os cursos da graduação. Estes conteúdos visam desenvolver competências a fim de que o estudante, futuro profissional formado na Instituição, tenha capacidade de abstração, análise e síntese da informação dos conhecimentos adquiridos e consciência para valorizar o respeito pela diversidade e multiculturalismo. Dessa forma, estas habilidades definem o perfil do estudante USC e participante do Syllabus.

$\mathrm{O}$ diferencial institucional estabelecido como diretriz consiste na busca da verdade e domínio do conhecimento científico de cada área, bem como o desenvolvimento atitudinal e procedimental agregados à construção do profissional. Dentro deste contexto, a Instituição reconhece a importância de não agir sem refletir, sem ponderar e sem buscar respostas.

Diante desse princípio, desde sua implantação a metodologia Syllabus tem sido submetida a processos avaliativos, envolvendo a perspectiva de se obter informação decorrente de diferentes olhares a fim de "ordenar fatos isolados que prevejam o que vai ocorrer como conseqüência de certas ações" (NOBREGA, 2004, p. 30).

Conforme prescreve Depresbiteris; Tavares (2009, p. 52), neste artigo, a informação, visando a orientação sobre os progressos e dificuldades, apresenta dados sobre uma consulta que a Coordenadoria Didática, em continuidade ao 
acompanhamento da Metodologia Syllabus, desenvolveu com os alunos dos cursos de Pedagogia, História, Arquitetura e Urbanismo e Ciências da Computação matriculados nas disciplinas Syllabus em 2009. Figari (1996) traduz esta coleta de dados como microestruturas.

A finalidade desta avaliação foi encontrar sinais de potencialidades e fragilidades sobre os procedimentos dos professores no processo de desenvolvimento da metodologia com base nos dois eixos fundamentais de sustentação do Syllabus, a leitura prévia e aplicação do Quiz.

Desta forma, na plataforma, num período de três semanas foram inseridos para o estudante responder, quando acessava a disciplina pela primeira vez, as perguntas: $O$ professor faz perguntas em sala de aula sobre o material da atividade prévia?; Você faz a leitura da atividade prévia antes da aula?

O sistema utilizado para a consulta, excluiu a possibilidade do estudante responder duas vezes, pois assim que as duas respostas eram dadas, automaticamente a tela com as perguntas era bloqueada e não aparecia novamente.

Nos cursos de Pedagogia, História, Arquitetura e Urbanismo e Ciências da Computação, o índice de respostas "sim", quando se questionou se o professor fez em sala de aula perguntas relacionadas à Atividade Prévia, correspondeu respectivamente a $91,78 \%, 95,81 \%, 89,78 \%$ e $82,07 \%$ conforme demonstra a figura 5. Quanto a segunda pergunta, se o estudante fez a leitura recomendada pelo professor antes da aula, o índice de respostas "sim" foi respectivamente de $99,32 \%, 97 \%, 95,7 \%$ e $88 \%$ (Figura 6).

Se compararmos os resultados obtidos pelos estudantes dos cursos aqui analisados na prova de conhecimentos gerais do ENADE com as repostas obtidas na pesquisa feita sobre a aplicação da Metodologia Syllabus, verificamos que existe uma correlação positiva entre o desempenho na avaliação e o envolvimento dos estudantes e docentes na Atividade prévia. Verifica-se no Quadro 1, que as maiores médias no ENADE foram obtidas pelos estudantes dos cursos de História e Pedagogia que apontaram na pesquisa maior participação nas leituras e atividades prévias propostas pela metodologia Syllabus.

No curso de História por exemplo, o fato de $97,1 \%$ dos estudantes aderirem a realização da leitura prévia recomendada pelo professor e $95,87 \%$ dos alunos confirmarem que os docentes das disciplinas do curso aplicam o Quiz, ou seja, fazem questionamentos em sala de aula sobre a atividade prévia recomendada, confirma a hipótese de que os resultados apresentados no ENADE e no CPC apresentam relação com a aplicação da Metodologia Syllabus. Portanto, o desempenho dos estudantes ingressantes dos cursos de História e Pedagogia destaca-se, quando comparado à média dos estudantes ingressantes no país, 
e certifica que o diferencial de qualidade apresentado nos resultados pode ter relação com o desenvolvimento da atividade prévia orientada, envolvendo leituras complementares.

O curso de Arquitetura obteve uma média de 50,4 no ENADE e a pesquisa apontou que $95,7 \%$ dos estudantes participam das atividades propostas nos Planos de aula. Já os estudantes do Curso de Ciência da Computação obtiveram no ENADE a média de 48,3, sendo a mais baixa entre os quatro cursos, associado ao índice de participação de $88 \%$, sendo este também o índice mais baixo. Esta correlação entre a performance dos estudantes no ENADE e a realização da leitura prévia orientada nos Planos de aula evidencia o importante papel da Metodologia Syllabus de estimular as leituras individuais e desenvolvimento de habilidades para compreensão de textos e o desenvolvimento da capacidade de pensar de uma maneira reflexiva e crítica.

\section{Quadro 1 - Resultados dos cursos avaliados no ENADE e índice de participação na Atividade Prévia da Metodologia Syllabus}

\begin{tabular}{|l|c|c|}
\hline \multicolumn{1}{|c|}{ Cursos } & Média no ENADE & Participação na Atividade Prévia \\
\hline Pedagogia & 54,1 & $99,32 \%$ \\
\hline História & 55,3 & $97,01 \%$ \\
\hline Arquitetura e Urbanismo & 50,6 & $95,7 \%$ \\
\hline Ciência da Computação & 48,3 & $88 \%$ \\
\hline
\end{tabular}

\section{CONSIDERAÇÕES FINAIS}

Percurso feito, essas breves considerações podem dar a impressão de estarmos próximos da meta. No entanto, a experiência de ter caminhado assegura apenas a certeza de que muito ainda resta de caminho a ser percorrido.

Este artigo, constituído de referenciais avaliativos e o trabalho pedagógico, sendo ambos complementares entre si, traz à tona que a avaliação sempre deve servir de bússola para que docentes e estudantes mantenham-se na rota que traçaram. Neste sentido, a avaliação é meio e não fim. Deve servir de pretexto para que o diálogo aconteça, baseado em evidências que espelhem como ambos organizam o trabalho pedagógico e expresse a intenção educativa que o sustenta.

Segundo Sordi (2008, p. 56) a avaliação realiza-se num misto de luz e sombra. Quanto mais nos debruçamos sobre este processo, mais percebemos 
como precisa ser desvendado. Todavia, uma primeira ruptura corresponde ao entendimento de sua inevitável face política e a intricada rede de interesses que a acompanha. Outro desafio é compreender e agir em conformidade com o entendimento de sua indissociação do trabalho pedagógico, sempre sujeito a todas as contradições que o perpassam.

Analisar o processo de ensino e aprendizagem, a qualidade e a coerência dos diversos indicadores dos cursos tem sempre por finalidade orientar docentes e estudantes com suas diferentes interfaces.

Acreditamos que o desafio seja conseguir colocar uma preocupação importante com a questão da formação, compartilhar esta preocupação ampla ao que se refere à avaliação numa lógica de inclusão e não ao contrário.

\section{REFERÊNCIAS}

ASSMANN, Hugo; MO SUNG, Jung. Competência e sensibilidade solidária: educar para a esperança. Petrópolis: Vozes, 2000.

DEPRESBITERIS, Lea; TAVARES, Marialva Rossi. Diversificar é preciso: instrumentos e técnicas de avaliação de aprendizagem. São Paulo: Senac, 2009.

FIGARI, Gerard. Para uma referenciação das práticas de avaliação dos estabelecimento de ensino. In: ESTRELA, A.; NÓVOA, A. (Orgs.). Avaliações em educação: novas perspectivas. Lisboa: Educa.1996.

FOLKIS, Gesiane. SECOD 2010. Forum. Disponível em $<$ http://syllabus. usc.br/>. Acesso em: 2 mar. 2010.

GILLEN, Terry. A avaliação de desempenho. São Paulo Nobel, 2000.

HEVIA, Renato; ZÚÑIGA, Ricardo; SCHIEFELBEIN, Ernesto. La metodología Syllabus: una guia práctica. Perguntas frecuentes. In: SCHIEFELBEIN, Ernesto; ZÚÑIGA, Ricardo. EI Syllabus: viviendo un aprendizaje autónomo. Santiago de Chile: Universidad Santo Tomás, 2002.

HOFFMANN, Jussara. Avaliação mediadora: uma prática em construção da pré-escola. A Universidade. 14. ed. Porto Alegre: Mediação, 1993.

LIBÂNEO, José Carlos. Didática. São Paulo: Cortez, 1992. 
LUCKESI, Cipriano Carlos. Avaliação da aprendizagem escolar. São Paulo: Cortez, 2002.

MACHADO, Nilson José. Epistemologia e didática: as concepções de conhecimento e inteligência e a prática docente. São Paulo: Cortez, 2002.

MASETTO, Marcos Tarcisio. Atividades pedagógicas no cotidiano da sala de aula universitária: reflexões e sugestões práticas. In: CASTANHO, Sérgio; CASTANHO, Maria Eugênia (Org.). Temas e textos em metodologia do ensino superior. Campinas: Papirus, 2001.

NOBREGA, Clemente. A ciência da gestão marketing, inovação, estratégia. Um físico explica a gestão - a maior inovação do século XX como uma ciência. 2 ed. Rio de Janeiro: Senac, 2004.

NORONHA. Maria Izabel Azevedo. Inovações do MEC são um passo importante para o Ensino Médio. Revista Educação \& Cidadania, Campinas, v. 8, n. 1, 2009.

REQUENA, Helio. SECOD 2010. Forum. Disponível em: < http://syllabus. usc.br/>. Acesso em: 2 ma. 2010.

RODRIGUES, Edlene do Socorro Tavares. Aprendizagens através da avaliação formativa, 2008. Disponível em: <http://www.pedagogia.com.br/ artigos/avaliacaoformativa/>. Acesso em: 20 jun. 2010.

SANTOS, Marisa Aparecida Pereira; NASKASHIMA, Rosária Helena Ruiz; PEGORARO Carolina Nunes; ZUCCARI, Patrícia. Ensinar e aprender com a Metodologia Syllabus. Revista de Educação AEC, Brasília, n.150, p. 21-27, jan./jun.. 2009.

SORDI, Mara Regina Lemes. A Docência universitária e o dilema da formação pedagógica para a produção de uma avaliação da aprendizagem conseqüente. Revista Educação PUC, Campinas, n. 25, p. 47-58, nov. 2008.

SORDI, Mara Regina Lemes. Da avaliação da aprendizagem à avaliação institucional: aprendizagens necessárias. Avaliação, Campinas; Sorocaba, v. 14, n. 2, p. 313-336, jul. 2009.

TEIXEIRA, Edlene. Aprendizagens por meio da avaliação formativa. Revista de Educação ANEC, Brasília, v. 38, n. 150, p. 29-35, jan./jun. 2009. 
USC - UNIVERSIDADE SAGRADO CORAÇÃO. Projeto Pedagógico do Curso de Pedagogia. Bauru, 2008.

USC - UNIVERSIDADE SAGRADO CORAÇÃO. Projeto Pedagógico do Curso de História. Bauru, 2008.

USC - UNIVERSIDADE SAGRADO CORAÇÃO. Projeto Pedagógico do Curso de Arquitetura e Urbanismo. Bauru, 2008.

USC - UNIVERSIDADE SAGRADO CORAÇÃO. Projeto Pedagógico do Curso de Ciências da Computação. Bauru, 2008

USC - UNIVERSIDADE SAGRADO CORAÇÃO. Coordenadoria Didática.Guia didático Syllabus. Informações gerais para professores, Coordenadoria Didática, 2010, p. 2. Disponível em: <http://syllabus.usc. br/>, Acesso em: 2 mar. 2010.

WACHOWICZ, Lílian Anna. A dialética da avaliação da aprendizagem na pedagogia diferenciada. In: CASTANHO, Sérgio; CASTANHO, Maria Eugênia (Orgs.). O que há de novo na educação superior: do projeto pedagógico à prática transformadora. Campinas: Papirus, 2000. p. 95-132.

ZABALA, Antoni. A prática educativa: como ensinar. Porto Alegre: Artmed,1998. 